\title{
A Computational Study of Optoelectronic and Charge Transport Properties of Purine Nucleobases Dinucleotides Compounds
}

\author{
Kimberly Madison \\ Jackson State University \\ Wojciech Kolodziejczyk \\ Jackson State University \\ Karina Kapusta \\ Jackson State University \\ Glake Hill ( $\square$ glakeh@icnanotox.org ) \\ Jackson State University https://orcid.org/0000-0002-7947-5556
}

\section{Research Article}

Keywords: optoelectronic devices, polymers, nucleobases, charge transfer

Posted Date: November 4th, 2021

DOI: https://doi.org/10.21203/rs.3.rs-854923/v1

License: (c) (i) This work is licensed under a Creative Commons Attribution 4.0 International License.

Read Full License 


\section{Abstract}

Optoelectronic and charge transport properties of eight novel compounds are presented in this work. Density functional theory B3LYP was utilized to optimize all structures while time-dependent density functional theory was utilized for vertical excitation characteristics. Gas and solvent phases (water, THF, and DCM) were evaluated to gain insight on solid-state and solution processed devices. While the solvent phases enhanced most of the charge transport properties, there was seen a blue-shift in their absorption wavelengths. However, C2, C4, C6, and C8 in THF absorption maxima were the highest and similar to those of the gas phase (605-652 nm). Extension of the polymer size decreased the HOMO-LUMO gap energy with $\mathrm{C} 7$ having the lowest energy gap in the gas phase. Although tuning the properties in optoelectronic devices is challenging, these findings will assist with the design of higher quality materials that could surpass the quality of inorganic devices.

\section{Introduction}

Optoelectronic devices have been a huge topic for decades. Recently, study has been dedicated to exploring enhanced capabilities that can result when organic molecules are integrated into these designs. [1] Devices such as organic field-effect transistors (OFETs), organic light-emitting diodes (OLEDs), and organic photovoltaic (OPV) devices use organic materials with $\pi$-conjugated systems as their semiconductor active layer.[2] These $\pi$-conjugated compounds are responsible for electrical conductivity in electronic devices. However, challenges may arise based on which material is chosen. This paper focuses on these challenges and discusses how: (1) the size of the material affects the distribution of electric charge throughout the system by $\pi$-delocalization, (2) the choice of side chains can influence the solubility of the material for production of solution-processed devices,[2]-[5] and (3) the choice of end groups can enhance the charge transport and optoelectronic properties.[6]-[8] Unlike their inorganic counterparts, choosing the appropriate organic molecules can both increase the quality of the device and lead to other advantages such as low production cost, easy fabrication, larger application scale, and increased flexibility.[9]-[12]

Design of organic optoelectronic devices can be based on not only small organic compounds, but also polymers and macromolecules. Polymers are long chains of repeated units that increase the $\pi$ delocalization of a system.[13] Some research has been done on how various properties of polymers affect their applications in energy storage and medicine.[14], [15] For example, Chowchows et al. designed six copolymers based on donor-acceptor model type D-A $-D-A_{2}$. As a result, these copolymers displayed a lower band gap by tuning properties such as the ionization potential (IP) and electron affinity (EA) leading to improved charge transport properties.[16] Zhang et al. studied copolymers based on indacenothiadiazole with thieno-[3,2-b] thiophene (TT) and benzothiadiazole (BT) end groups. In their work, the IP energies, maximum absorption $\left(\lambda_{\max }\right)$, and hole mobilities were determined. Although the results showed that the IP values were similar for both the BT and TT units, the maximum absorption and hole mobility were higher for the BT unit and lower for the TT unit which demonstrates how the choice of end groups can affect the optoelectronic and charge transport properties.[17] When incorporated in 
optoelectronic devices, biological molecules can potentially be used in the medical technology field for enhanced sensing, diagnosis, and imaging.[18], [19] Gomez et al. observed the IP energies and electron affinity (EA) trends of nucleobases. EA energies of purines (guanine and adenine) had generally lower values compare to pyrimidines (thymine, cytosine, and uracil). These results are related to whether the hole or electron is transported across the active layer. Lower values of EA energies favor the hole transport, while higher values benefit electron transport.[20] Another work[21] was dedicated to investigation of DNA polymers for use in bioorganic light emitting diodes that exhibited high photoemission properties and enhanced performance in optoelectronic devices. The properties that improve applications in a variety of fields were demonstrated. Merging polymers and DNA bases could be an advanced area of study for the future of medicine and technology.[22]

When studying charge transport, it is important to focus on the highest occupied molecular orbital (HOMO) and lowest unoccupied molecular orbital (LUMO) as they are important for optoelectronic devices as they can allow/disallow charge separation. Allowance of charge separation is preferred. This can help determine the localization and delocalization of electrons in a molecule.[23], [24] Since the HOMO/LUMO orbitals are important, it is a good idea to examine the global chemical reactivity descriptors (GCRD). These properties can help gain insight on the reactivity behavior of these compounds based on their molecular orbitals. The GCRDs discussed in this work include the hardness ( $\square$ ), chemical potential $(\mu)$, electronegativity $(\chi)$, and electrophilicity index $(\omega)$ and are termed below as described by Robert Parr and colleagues. While all the GCRDs below relates to the stability of a compound, the context in which they are defined are different.[25]-[28] The hardness is the ability to resist charge transfer within its environment. The chemical potential is the degree to which electrons can be removed from the equilibrium system. The electronegativity is the ability of a molecule to attract electrons. The last GCRD discussed in this work is the electrophilicity index which is the stabilization energy of a molecule when it is saturated by electrons from an external environment and predicts whether a molecule is strong electrophile. The hardness and electronegativity favors lower values while the chemical potential and electrophilicity index favors higher values. These parameters will help in determining how efficient the charge transfer will be.[29]-[33]

This study investigates the optoelectronic and charge transport properties of novel compounds based on purine nucleobase dinucleotides merged with a dibenzo-cyclopentadithiophene based polymer. The influence of aforementioned descriptors (i.e. size, sidechains, and end groups) was investigated to gain an insight on the charge transport and optoelectronic properties of these novel compounds. The analysis of these compounds not only include the above-mentioned charge transport properties, but also their absorption characteristics, reorganization energy, and ionization potential.

\section{Computational Methods}

In this work eight dibenzo-cyclopentadithiophene based polymers (C1-C8) were designed based on the scheme illustrated in Figure 1. These structures consist of the dibenzocyclopentadithiophene backbone varying in size (two or four monomers), the side chains based on adenine or guanine nucleotides, and the 
end groups comprised of one or two benzoic acids. Purines were chosen as the nucleobase because of lower electron affinity values compared to the pyrimidines which makes them favorable for hole transport in optoelectronic devices.

All calculations were studied in the ground state, unless otherwise stated, using the Gaussian 09 software package[34] was used to optimize the structures using Density Functional Theory (DFT) B3LYP functional[35] with 6-31G basis set. Frequency calculations were performed to assure the structures were at their minimum. In order to investigate the influence of a solvent all calculations were carried out in gas phase as well as solvent phases using the conductor like polarizable continuum model (C-PCM) in water and common organic solvents such as, tetrahydrofuran (THF) and dichloromethane (DCM).[36]-[39]

The reorganization energy is one of the main properties in determining the charge carrier mobility in electronic devices as it relates to the reorganization of a molecule from its initial to final states and vice versa. The reorganization energy can be calculated for hole transfer and electron transfer but for this study, we only focused on the hole transfer due to studies showing higher charge carrier mobility values for holes instead of electrons. The hole reorganization energy is shown in equation 5 :

$\lambda_{\mathrm{h}}=\left(E_{+}^{*}-\mathrm{E}_{+}\right)+\left(\mathrm{E}^{*}-\mathrm{E}\right)$

in which,

$E_{+}^{*}$ is the single point (sp) energy of the cation at the geometry of the neutral molecule,

$\mathrm{E}_{+}$is the optimized geometry energy of the cation,

$E^{*}$ is the sp energy of the neutral molecule at the geometry of their ionic states,

$E$ is the energy of the optimized neutral molecule.

The reorganization energy must be low in order to have a fast charge transfer rate leading to good charge transport properties such as high charge carrier mobility values.[40]-[43]

The charge injection efficiency is another important property for optoelectronic devices. For this study, the term that relates to observing the properties of charge injection is the ionization potential (IP). This requires removing the electron from the $\mathrm{HOMO}$ and injecting it into the LUMO. For the electron to be injected into the empty LUMO orbital, the energy of the IP must be low. The IP is shown in equation 6.

$\mathrm{IP}=E_{+}^{*}-\mathrm{E}(6)$

In this case, we refer to the vertical IP in which the ions are not in their relaxed geometry but rather in the geometry of the neutral molecule.[44]-[49]

Adsorption properties were studied using time-dependent density functional theory (TD-DFT). Within the absorption characteristics the main property to observe is the maximum absorption wavelength ( $\lambda$-max). 
To aide in improving these electronic devices mentioned earlier in this work, researchers have been looking into materials that can absorb near the infrared region (IR) of the electromagnetic spectrum. Although the $\lambda$-max is the most important property in this research, the excitation energy, the major percent contributions, and the molecular orbitals transitions[50] were also calculated.

\section{Results And Discussion}

All structures were optimized in their ground state (Figure 1S, Supporting Information). Compounds C1, $\mathrm{C} 2, \mathrm{C} 5$, and $\mathrm{C} 6$ had adenine nucleotides as their side chains while $\mathrm{C} 3, \mathrm{C} 4, \mathrm{C} 7$, and $\mathrm{C} 8$ had guanine ones. Interestingly, some structures exhibited bending along the O-P-O-P dihedral angles of the side chains while others were more straightened (Figure 2, Table 1). The solvent and a nature of nucleotide played a major role in the bending of these compounds. Most of the polymers containing guanine displayed bending, except for $\mathrm{C} 3$ and $\mathrm{C} 4$ in gas phase and $\mathrm{C} 4$ in THF phase. Presumably, the oxygen atom on the guanine plays a part in the bending, especially when exposed to the solvent. In some cases, the bending of these molecules was also affected by having two benzoic acid end groups instead of one. 
Table 1

O-P-O-P dihedral angles of the compounds in gas and solvent phases.

\begin{tabular}{|c|c|c|c|c|c|c|c|c|c|c|c|}
\hline \multirow{2}{*}{\multicolumn{2}{|c|}{$\begin{array}{l}\text { Gas } \\
\text { C1 }\end{array}$}} & & & & & \multicolumn{6}{|c|}{ Water } \\
\hline & & & C2 & & & C1 & & & C2 & & \\
\hline \multirow[t]{2}{*}{$\varphi$} & 1 & 2 & \multirow[t]{2}{*}{$\varphi$} & 1 & 2 & \multirow[t]{2}{*}{$\varphi$} & 1 & 2 & \multirow[t]{2}{*}{$\varphi$} & 1 & 2 \\
\hline & $156^{\circ}$ & $156^{\circ}$ & & $157^{\circ}$ & $157^{\circ}$ & & $105^{\circ}$ & $110^{\circ}$ & & $104^{\circ}$ & $111^{\circ}$ \\
\hline \multicolumn{3}{|c|}{ C3 } & \multicolumn{3}{|c|}{$\mathrm{C} 4$} & \multicolumn{3}{|c|}{ C3 } & \multicolumn{3}{|c|}{ C4 } \\
\hline \multirow[t]{2}{*}{$\varphi$} & 1 & 2 & \multirow[t]{2}{*}{$\varphi$} & 1 & 2 & \multirow[t]{2}{*}{$\varphi$} & 1 & 2 & \multirow[t]{2}{*}{$\varphi$} & 1 & 2 \\
\hline & $156^{\circ}$ & $157^{\circ}$ & & $158^{\circ}$ & $156^{\circ}$ & & $130^{\circ}$ & $110^{\circ}$ & & $113^{\circ}$ & $81^{\circ}$ \\
\hline \multicolumn{3}{|c|}{ C5 } & \multicolumn{3}{|c|}{ C6 } & \multicolumn{3}{|c|}{ C5 } & \multicolumn{3}{|c|}{ C6 } \\
\hline \multirow[t]{4}{*}{$\varphi$} & 1 & 2 & \multirow[t]{4}{*}{$\varphi$} & 1 & 2 & \multirow[t]{4}{*}{$\varphi$} & 1 & 2 & \multirow[t]{4}{*}{$\varphi$} & 1 & 2 \\
\hline & $156^{\circ}$ & $155^{\circ}$ & & $156^{\circ}$ & $155^{\circ}$ & & $66^{\circ}$ & $109^{\circ}$ & & $126^{\circ}$ & $118^{\circ}$ \\
\hline & 3 & 4 & & 3 & 4 & & 3 & 4 & & 3 & 4 \\
\hline & $155^{\circ}$ & $156^{\circ}$ & & $157^{\circ}$ & $156^{\circ}$ & & $107^{\circ}$ & $66^{\circ}$ & & $108^{\circ}$ & $107^{\circ}$ \\
\hline \multicolumn{3}{|c|}{ C7 } & \multicolumn{3}{|c|}{ C8 } & \multicolumn{3}{|c|}{ C7 } & \multicolumn{3}{|c|}{$\mathrm{C} 8$} \\
\hline \multirow[t]{4}{*}{$\varphi$} & 1 & 2 & \multirow[t]{4}{*}{$\varphi$} & 1 & 2 & \multirow[t]{4}{*}{$\varphi$} & 1 & 2 & $\varphi$ & 1 & 2 \\
\hline & $156^{\circ}$ & $149^{\circ}$ & & $156^{\circ}$ & $155^{\circ}$ & & $106^{\circ}$ & $139^{\circ}$ & & $57^{\circ}$ & $65^{\circ}$ \\
\hline & 3 & 4 & & 3 & 4 & & 3 & 4 & & 3 & 4 \\
\hline & $60^{\circ}$ & $60^{\circ}$ & & $140^{\circ}$ & $60^{\circ}$ & & $65^{\circ}$ & $64^{\circ}$ & & $136^{\circ}$ & $65^{\circ}$ \\
\hline TH & & & & & & DC & & & & & \\
\hline C1 & & & $\mathrm{C} 2$ & & & C1 & & & C2 & & \\
\hline$\varphi$ & 1 & 2 & $\varphi$ & 1 & 2 & $\varphi$ & 1 & 2 & $\varphi$ & 1 & 2 \\
\hline & $138^{\circ}$ & $137^{\circ}$ & & $116^{\circ}$ & $107^{\circ}$ & & $102^{\circ}$ & $134^{\circ}$ & & $105^{\circ}$ & $133^{\circ}$ \\
\hline C3 & & & C4 & & & C3 & & & C4 & & \\
\hline$\varphi$ & 1 & 2 & $\varphi$ & 1 & 2 & $\varphi$ & 1 & 2 & $\varphi$ & 1 & 2 \\
\hline & $55^{\circ}$ & $54^{\circ}$ & & $136^{\circ}$ & $134^{\circ}$ & & $55^{\circ}$ & $55^{\circ}$ & & $55^{\circ}$ & $55^{\circ}$ \\
\hline C5 & & & C6 & & & C5 & & & C6 & & \\
\hline$\varphi$ & 1 & 2 & $\varphi$ & 1 & 2 & $\varphi$ & 1 & 2 & $\varphi$ & 1 & 2 \\
\hline & $133^{\circ}$ & $134^{\circ}$ & & $135^{\circ}$ & $136^{\circ}$ & & $118^{\circ}$ & $132^{\circ}$ & & $138^{\circ}$ & $135^{\circ}$ \\
\hline & 3 & 4 & & 3 & 4 & & 3 & 4 & & 3 & 4 \\
\hline
\end{tabular}




\begin{tabular}{|c|c|c|c|c|c|c|c|c|c|c|c|}
\hline \multicolumn{6}{|c|}{ Gas } & \multicolumn{6}{|c|}{ Water } \\
\hline & $134^{\circ}$ & $135^{\circ}$ & & $138^{\circ}$ & $136^{\circ}$ & & $63^{\circ}$ & $135^{\circ}$ & & $137^{\circ}$ & $134^{\circ}$ \\
\hline C7 & & & C8 & & & C7 & & & C8 & & \\
\hline \multirow[t]{4}{*}{$\varphi$} & 1 & 2 & $\varphi$ & 1 & 2 & $\varphi$ & 1 & 2 & $\varphi$ & 1 & 2 \\
\hline & $136^{\circ}$ & $138^{\circ}$ & & $55^{\circ}$ & $130^{\circ}$ & & $64^{\circ}$ & $138^{\circ}$ & & $55^{\circ}$ & $128^{\circ}$ \\
\hline & 3 & 4 & & 3 & 4 & & 3 & 4 & & 3 & 4 \\
\hline & $64^{\circ}$ & $64^{\circ}$ & & $137^{\circ}$ & $64^{\circ}$ & & $64^{\circ}$ & $135^{\circ}$ & & $141^{\circ}$ & $64^{\circ}$ \\
\hline
\end{tabular}

The absorption spectra were calculated for all studied here compounds in their gas and solvent phases (water, THF, and DCM). The charted absorption spectra for all phases are shown in Figure 3, while Table 1S (Supporting Information) displays the detailed information on maximum wavelength, excitation energy, major percent contributions, and the electronic transitions. The maximum wavelengths of absorption for the solvent phases mostly had a blue-shift (increased in excitation energy) when compared to the gas phase. However, for $\mathrm{C} 2, \mathrm{C} 4, \mathrm{C} 6$, and C8 in THF maximum of absorption had a similar wavelength as in gas phase, which also leaded to their excitation energy and major percent contributions being similar. None of the compounds in this study showed to absorb near the IR region of the spectrum. The electronic transitions for tmajority of the compounds were due to the HOMO to LUMO transitions, excluding $\mathrm{C} 3$ and $\mathrm{C} 4$ in the gas phase, where it was due to the HOMO-1 to LUMO transitions. These results were followed by a more extensive investigation into the molecular orbitals of these compounds.

Figure 4 displays the visualization of the molecular orbital transitions, the HOMO and LUMO energies, and the HOMO-LUMO energy gap. For all the compounds the HOMO and LUMO orbitals were located along the dibenzocyclopentadithiophene backbone, except for the HOMO orbitals of C3 and C4 which is positioned along the top side chain of the guanine molecule. The HOMO-1 molecular orbitals of $\mathrm{C} 3$ and $\mathrm{C} 4$ in the gas phase had similar orbital shapes as all the other compounds, shown in Figure 5 along with their HOMO-1 to LUMO energy gap. This explained why the major \% contributions of the above-mentioned compounds are due to the HOMO-1 to LUMO transitions. The HOMO-LUMO energy difference illustrated in Figure 4 showed that $\mathrm{C} 7$ in the gas phase had the lowest energy gap. This structure exhibited the HOMO and LUMO orbitals different from the others, with the HOMO being located farther away from the benzoic acid end group and the LUMO being closer to the benzoic acid end group.

The reorganization energy, the ionization potential energy as well as the global chemical reactivity descriptors were calculated (Table 2S, Supporting Information). The reorganization energy for all compounds was lower in the solvent phases than in the gas phase. It was also seen that the reorganization energy of compounds containing 4 monomers was lower compared to ones made of two monomers, except for C2 and C6 in DCM phase. Having lower values of the reorganization energy, ionization potential energy, and electronegativity in solvent suggested that solvation can help improve the charge transfer properties by providing a higher charge transfer rate and a more efficient charge injection. 
The chemical potential calculation showed a higher tendency of electrons escaping the system when solvation model was used, which suggests better donor properties of studied compounds in solvent phase than in gas phase. The hardness was also improved in solvent phases. All these trends were illustrated in Figure 6. C7, in the gas phase, exhibited distinctive extremum properties when compared to the other compounds. It is believed that this could be caused by the delocalization of the molecular orbitals, shown in $\mathrm{C7}$, resulted in lower HOMO-LUMO energy gaps.

Also, it was noted that the bending of these molecules resulted in lowering the reorganization energy and the ionization potential energy. This can signify that bending on the side chains can be associated with the reorganization energy and the ionization energy directly.

Overall, the size of the compounds increased the absorption maxima and lowers the energy for the reorganization energy, ionization potential, and the hardness. The energy gap was also lower for compounds where $n=4$. While no significant changes occurred for the different side chains, in many cases the guanine side chain improved some of these properties. The choice of one or two end groups did not affect any of the properties listed above, however, it can be seen that it plays a part in the bending of the compounds.

\section{Conclusion}

Eight novel compounds based on purine dinucleotide polymers were presented. The bending of the side chains, due to different solvent phases, of these compounds played a significant role in the optoelectronic and charge transport properties. Increasing the size of the polymers resulted in an increased $\lambda$-max for all phases. It also lowered the reorganization energy, ionization potential energy, and the hardness. Overall, compound C7 in the gas phase had the most superior results and will be looked at for further studies. The insights gained from this work will help better develop and tune the properties of DNA-based polymers for use in optoelectronic devices.

\section{Declarations}

\section{Declaration of Competing Interest}

The authors declare that they have no known competing financial interests or personal relationships that could have appeared to influence the work reported in this paper.

\section{Funding and Acknowledgement}

The authors want to thank the National Science Foundation [Grant: NSF/CREST HRD-1547754] and [Grant NSF/EPSCOR CEMOs-1757220] for financial support.

\section{Availability of data and material}

All supporting data is available within the supplementary material and available upon request. 


\section{Code Availability}

N/A

\section{Authors' Contributions}

All authors contributed to the study conception and design. Computational work and calculations were performed by Kimberly Madison, Wojciech Kolodziejczyk*, Karina Kapusta, and supervised by Glake Hill. The first draft of the manuscript was written by Kimberly Madison and all authors commented on previous versions of the manuscript. All authors read and approved the final manuscript.

\section{References}

1. S. R. Forrest, M. E. Thompson, Chem. Rev., 2007, DOI:10.1021/cr0501590.

2. Z. B. Henson, K. Müllen, G. C. Bazan, Design strategies for organic semiconductors beyond the molecular formula, Nature Chemistry. 2012.

3. M. J. Małachowski, J. Zmija, Opto-electronics Rev., 2010, DOI:10.2478/s11772-010-0008-9.

4. H. Sirringhaus, Device physics of solution-processed organic field-effect transistors, Advanced Materials. 2005.

5. F. Zhang, Y. Hu, T. Schuettfort, C. A. Di, X. Gao, C. R. McNeill, L. Thomsen, S. C. B. Mannsfeld, W. Yuan, H. Sirringhaus, D. Zhu, J. Am. Chem. Soc., 2013, DOl:10.1021/ja311469y.

6. U. Koldemir, S. R. Puniredd, M. Wagner, S. Tongay, T. D. McCarley, G. D. Kamenov, K. Müllen, W. Pisula, J. R. Reynolds, Macromolecules, 2015, DOl:10.1021/acs.macromol.5b01252.

7. S. Kim, J. K. Park, Y. D. Park, RSC Adv., 2014, DOI:10.1039/c4ra05873a.

8. J. K. Park, J. Jo, J. H. Seo, J. S. Moon, Y. D. Park, K. Lee, A. J. Heeger, G. C. Bazan, Adv. Mater., 2011, DOI:10.1002/adma.201004629.

9. S. T. Bromley, M. Mas-Torrent, P. Hadley, C. Rovira, J. Am. Chem. Soc., 2004, DOI:10.1021/ja049762a.

10. M. C. Chen, S. Vegiraju, C. M. Huang, P. Y. Huang, K. Prabakaran, S. L. Yau, W. C. Chen, W. T. Peng, I. Chao, C. Kim, Y. T. Tao, J. Mater. Chem. C, 2014, DOI:10.1039/c4tc01454e.

11. L. Torsi, M. Magliulo, K. Manoli, G. Palazzo, Chem. Soc. Rev., 2013, DOI:10.1039/c3cs60127g.

12. T. W. Kelley, P. F. Baude, C. Gerlach, D. E. Ender, D. Muyres, M. A. Haase, D. E. Vogel, S. D. Theiss, Recent progress in organic electronics: Materials, devices, and processes, Chemistry of Materials. 2004.

13. S. R. Forrest, The path to ubiquitous and low-cost organic electronic appliances on plastic, Nature. 2004.

14. A. M. Bryan, L. M. Santino, Y. Lu, S. Acharya, J. M. D’Arcy, Conducting Polymers for Pseudocapacitive Energy Storage, Chemistry of Materials. 2016.

15. N. Casado, G. Hernández, H. Sardon, D. Mecerreyes, Current trends in redox polymers for energy and medicine, Progress in Polymer Science. 2016. 
16. C. L. Chochos, S. Drakopoulou, A. Katsouras, B. M. Squeo, C. Sprau, A. Colsmann, V. G. Gregoriou, A. P. Cando, S. Allard, U. Scherf, N. Gasparini, N. Kazerouni, T. Ameri, C. J. Brabec, A. Avgeropoulos, Macromol. Rapid Commun., 2017, DOI:10.1002/marc.201600720.

17. W. Zhang, J. Smith, S. E. Watkins, R. Gysel, M. McGehee, A. Salleo, J. Kirkpatrick, S. Ashraf, T. Anthopoulos, M. Heeney, I. McCulloch, J. Am. Chem. Soc., 2010, DOI:10.1021/ja1049324.

18. H. Xu, L. Yin, C. Liu, X. Sheng, N. Zhao, Recent Advances in Biointegrated Optoelectronic Devices, Advanced Materials. 2018.

19. D. T. Simon, E. O. Gabrielsson, K. Tybrandt, M. Berggren, Organic Bioelectronics: Bridging the Signaling Gap between Biology and Technology, Chemical Reviews. 2016.

20. E. F. Gomez, V. Venkatraman, J. G. Grote, A. J. Steckl, Exploring the Potential of Nucleic Acid Bases in Organic Light Emitting Diodes, Advanced Materials. 2015.

21. E. F. Gomez, V. Venkatraman, J. G. Grote, A. J. Steckl, Sci. Rep., 2014, DOI:10.1038/srep07105.

22. M. J. U. Cho, U. R. A. Lee, Y. S. Kim, J. Shin, Y. M. Kim, Y. W. Park, B. K. Ju, J. I. L. Jin, D. H. Choi, J. Polym. Sci. Part A Polym. Chem., 2010, DOI:10.1002/pola.23958.

23. T. M. McCormick, C. R. Bridges, E. I. Carrera, P. M. Dicarmine, G. L. Gibson, J. Hollinger, L. M. Kozycz, D. S. Seferos, Macromolecules, 2013, DOI:10.1021/ma4005023.

24. B. G. Kim, X. Ma, C. Chen, Y. le, E. W. Coir, H. Hashemi, Y. Aso, P. F. Green, J. Kieffer, J. Kim, Adv. Funct. Mater., 2013, DOI:10.1002/adfm.201201385.

25. M. Bourass, A. Touimi Benjelloun, M. Benzakour, M. Mcharfi, F. Jhilal, F. Serein-Spirau, J. Marc Sotiropoulos, M. Bouachrine, J. Saudi Chem. Soc., 2017, DOI:10.1016/j.jscs.2017.01.001.

26. M. Bourass, A. T. Benjelloun, M. Benzakour, M. Mcharfi, M. Hamidi, S. M. Bouzzine, M. Bouachrine, Chem. Cent. J., 2016, DOI:10.1186/s13065-016-0216-6.

27. G. I. Cárdenas-Jirón, J. H. Zagal, J. Electroanal. Chem., 2001, DOI:10.1016/S0022-0728(00)00434-4.

28. E. Matito, M. V. Putz, J. Phys. Chem. A, 2011, D0I:10.1021/jp200731d.

29. J. L. Gázquez, A. Cedillo, A. Vela, J. Phys. Chem. A, 2007, DOI:10.1021/jp065459f.

30. B. Amel, T. Abbaz, A. Gouasmia, D. Villemin, J. Adv. Chem., 2017, DOl:10.24297/jac.v13i12.6072.

31. L. R. Domingo, M. Ríos-Gutiérrez, P. Pérez, Applications of the conceptual density functional theory indices to organic chemistry reactivity, Molecules. 2016.

32. R. G. Parr, W. Yang, Annu. Rev. Phys. Chem., 1995, DOI:10.1146/annurev.pc.46.100195.003413.

33. C. L. Heredia, V. Ferraresi-Curotto, M. B. López, Comput. Mater. Sci., 2012, DOI:10.1016/j.commatsci.2011.09.005.

34. M. J. Frisch, G. W. Trucks, H. E. Schlegel, G. E. Scuseria, M. A. Robb, J. R. Cheeseman, G. Scalmani, V. Barone, G. A. Petersson, F. O., J. B. Foresman, J. D. Fox, Gaussian 16, Gaussian, Inc., Wallingford CT,. 2016.

35. K. Burke, J. Chem. Phys., 2012, DOI:10.1063/1.4704546.

36. H. Wang, B. Hsieh, G. Jiménez-Osés, P. Liu, C. J. Tassone, Y. Diao, T. Lei, K. N. Houk, Z. Bao, Small, 2015, DOI:10.1002/smll.201401890. 
37. P. L. M. Linsha, R. Karamel, S. Ramakrishnan, M. George, Chem. Sci. Trans., 2017, DOI:10.7598/cst2017.1388.

38. T. M. Eggenhuisen, Y. Galagan, E. W. C. Coenen, W. P. Voorthuijzen, M. W. L. Slaats, S. A. Kommeren, S. Shanmuganam, M. J. J. Coenen, R. Andriessen, W. A. Groen, Sol. Energy Mater. Sol. Cells, 2015, DOI:10.1016/j.solmat.2014.12.014.

39. W. Zhao, S. Zhang, Y. Zhang, S. Li, X. Liu, C. He, Z. Zheng, J. Hou, Adv. Mater., 2018, DOI:10.1002/adma.201704837.

40. F. Sun, R. Jin, Arab. J. Chem., 2017, DOI:10.1016/j.arabjc.2013.11.037.

41. J. Mei, Y. Diao, A. L. Appleton, L. Fang, Z. Bao, Integrated materials design of organic semiconductors for field-effect transistors, Journal of the American Chemical Society. 2013.

42. E. F. Oliveira, F. C. Lavarda, Polymer (Guildf)., 2016, DOI:10.1016/j.polymer.2016.07.003.

43. K. Takimiya, S. Shinamura, I. Osaka, E. Miyazaki, Thienoacene-based organic semiconductors, Advanced Materials. 2011.

44. H. Ma, N. Liu, J. D. Huang, Sci. Rep., 2017, DOI:10.1038/s41598-017-00410-6.

45. Y. R. Shi, H. ling Wei, Y. ting Shi, Y. F. Liu, Synth. Met., 2017, DOI:10.1016/j.synthmet.2016.11.028.

46. X. K. Chen, L. Y. Zou, S. Huang, C. G. Min, A. M. Ren, J. K. Feng, C. C. Sun, Org. Electron., 2011, DOI:10.1016/j.orgel.2011.03.029.

47. S. Chai, S. H. Wen, K. L. Han, Org. Electron., 2011, DOI:10.1016/j.orgel.2011.07.008.

48. S. Chai, S. H. Wen, J. D. Huang, K. L. Han, J. Comput. Chem., 2011, DOI:10.1002/jcc.21904.

49. Y. C. Hung, J. C. Jiang, C. Y. Chao, W. F. Su, S. T. Lin, J. Phys. Chem. B, 2009, DOI:10.1021/jp9018603.

50. L. Dou, Y. Liu, Z. Hong, G. Li, Y. Yang, Chem. Rev., 2015, DOI:10.1021/acs.chemrev.5b00165.

\section{Figures}

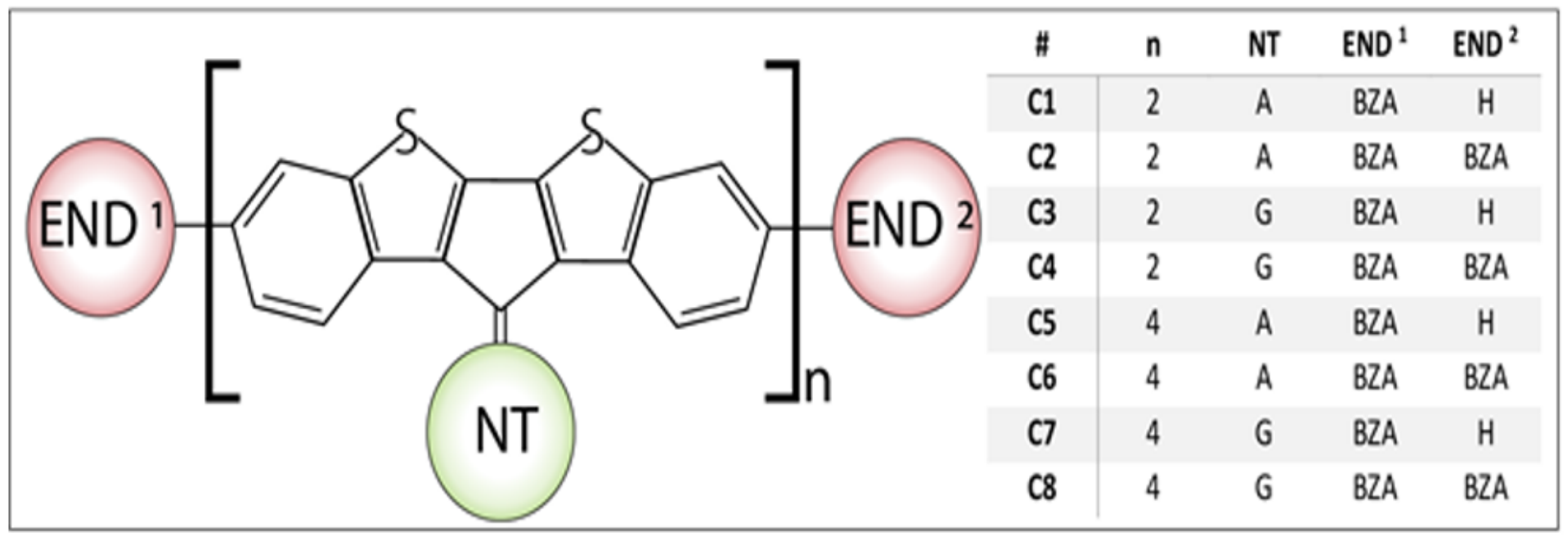

Figure 1 
Basic structure of the compounds C1-C8 used in this study. $n$ - is the number of monomers; NT nucleotide; A - adenine; $\mathrm{G}$ - guanine; BZA - benzoic acid; $\mathrm{H}$ - hydrogen atom.

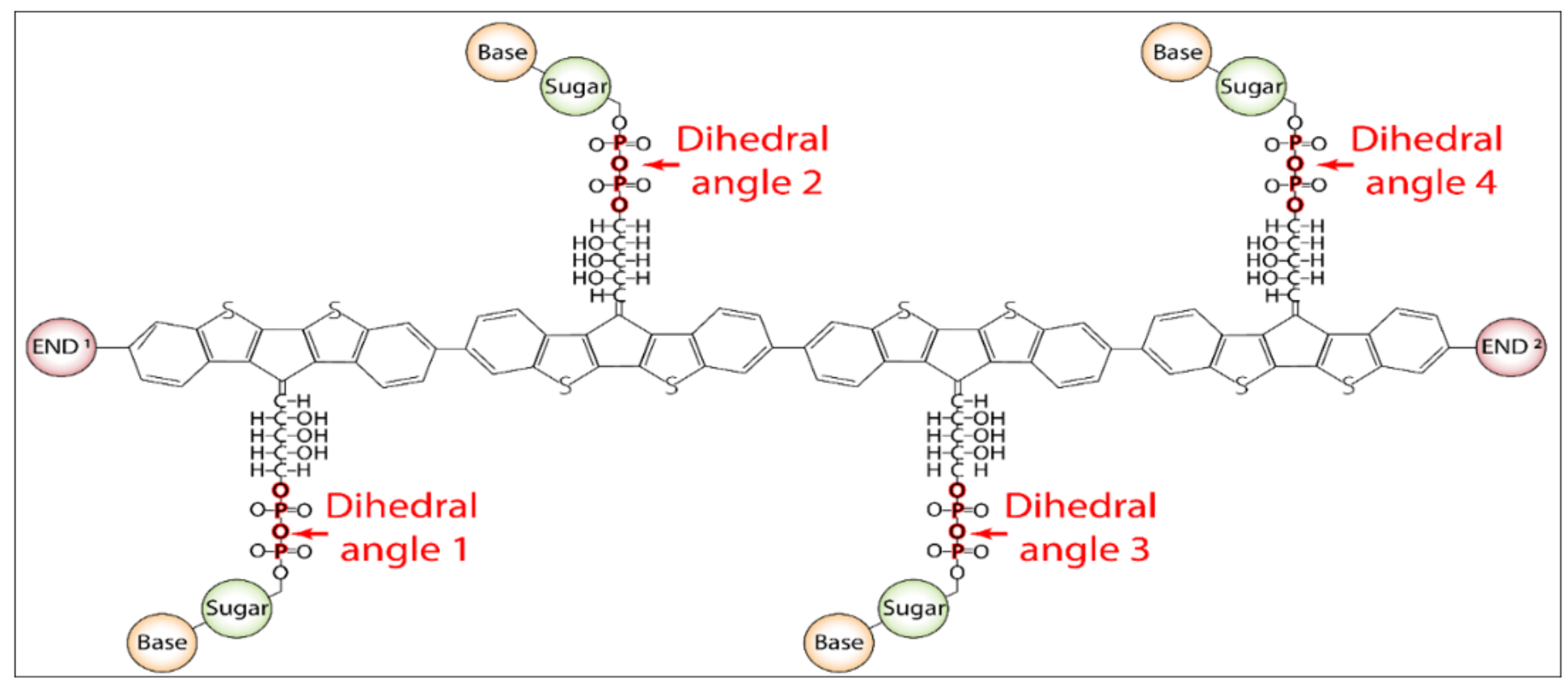

Figure 2

Scheme indicating dihedral angles that can be bent. 


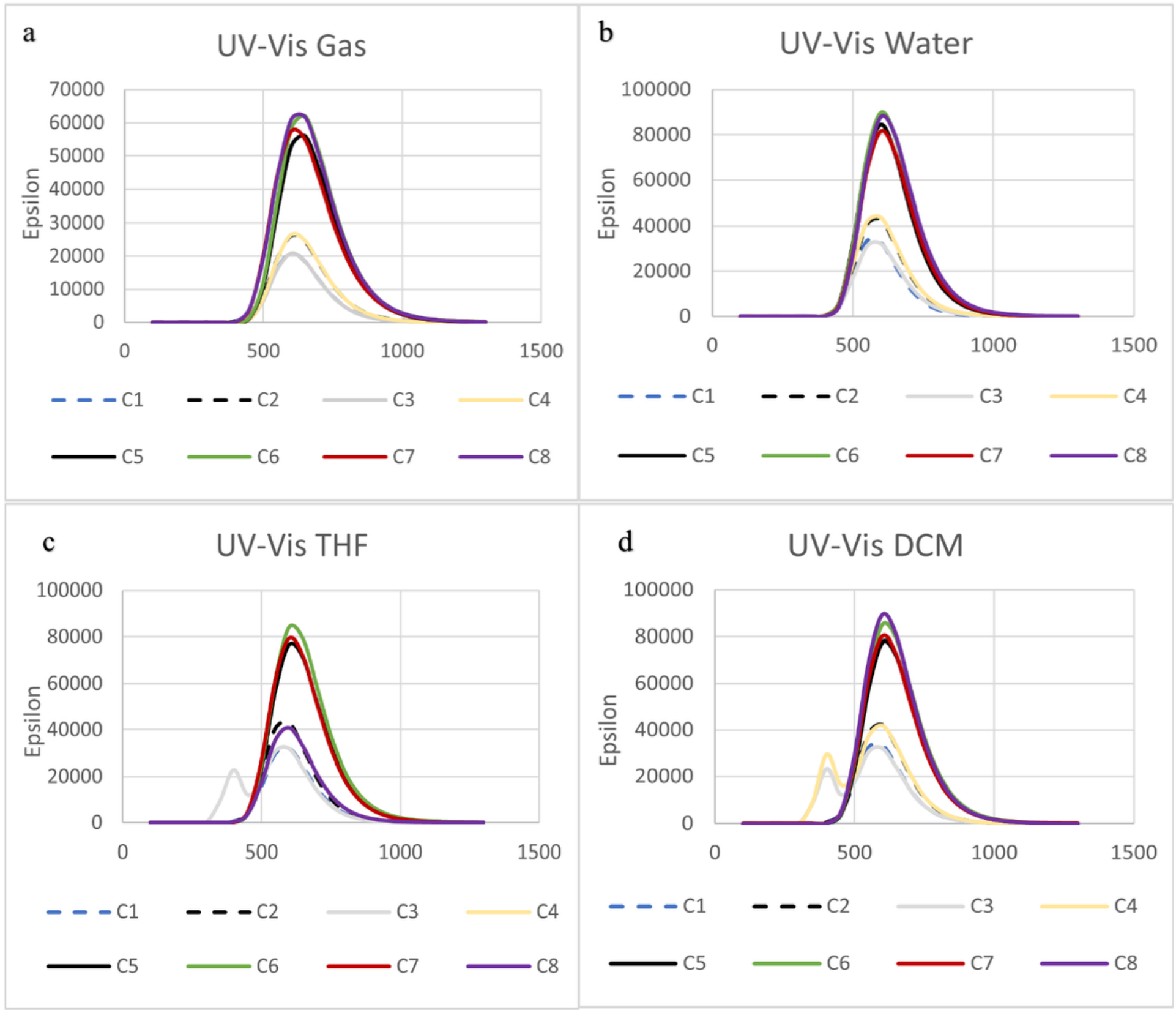

Figure 3

Calculated UV-Vis absorption spectra of all compounds in (a) gas, (b) water, (c) THF, and (d) DCM phases. 


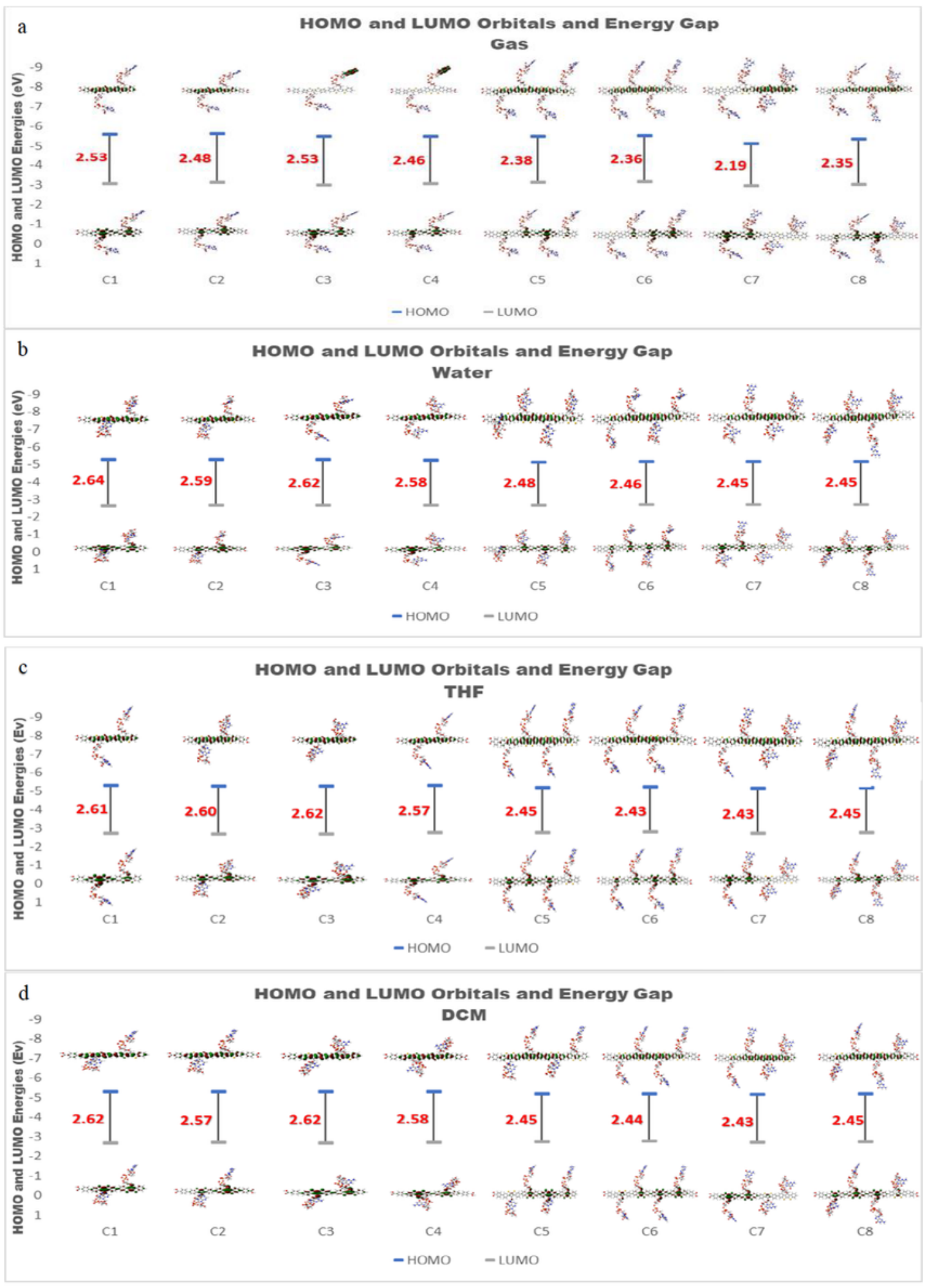

\section{Figure 4}

Visualization of the HOMO and LUMO orbitals including the HOMO-LUMO energy gap for (a) gas, (b) water, (c) THF, and (d) DCM phases. 

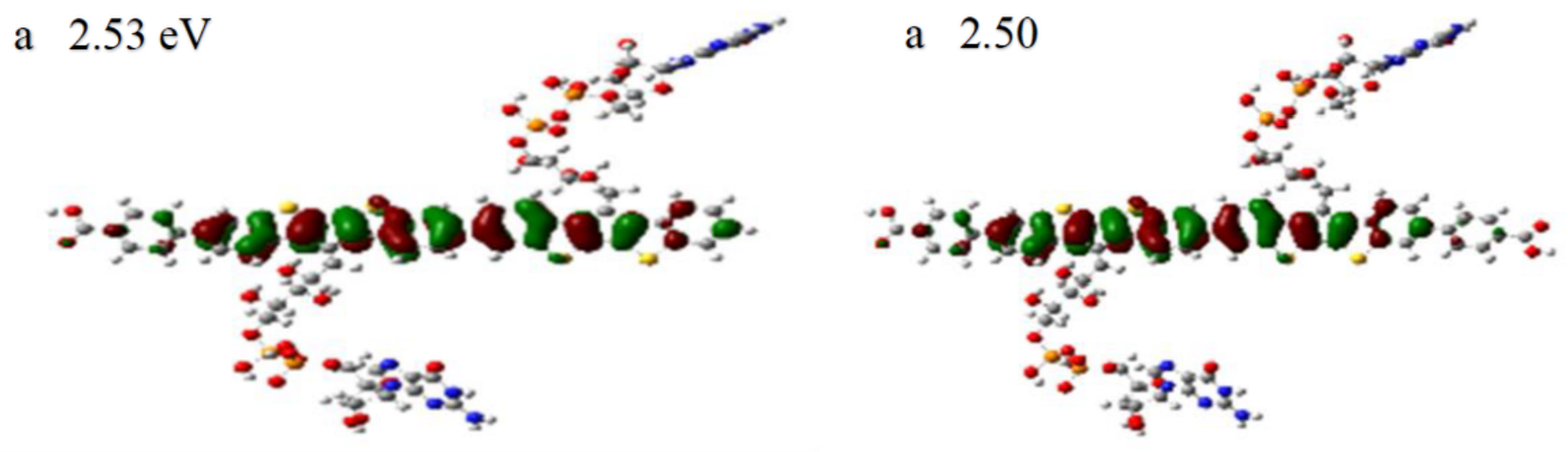

Figure 5

Visualization of the HOMO-1 orbitals and the HOMO-1 to LUMO energy gap for (a) C3 and (b) C4 in the gas phase. 
a Trend in Reorganization Energy

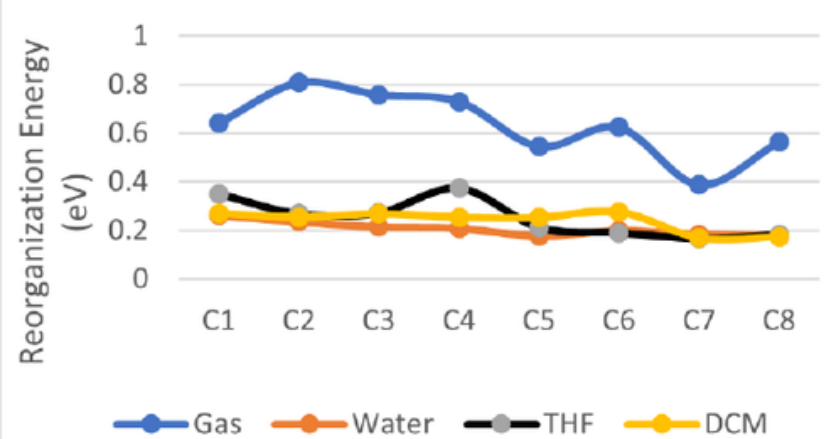

C

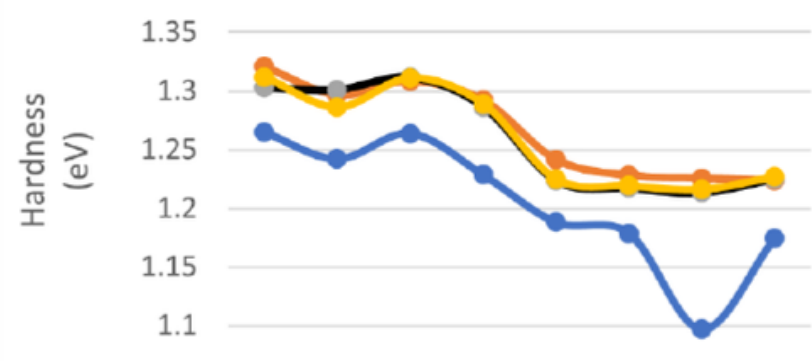

1.05

$\begin{array}{llllllll}\mathrm{C} 1 & \mathrm{C} 2 & \mathrm{C} 3 & \mathrm{C} 4 & \mathrm{C} 5 & \mathrm{C} 6 & \mathrm{C} 7 & \mathrm{C} 8\end{array}$

$\multimap$ Gas $\longrightarrow$ Water - THF $\longrightarrow$ DCM

e Trend in Electronegativity

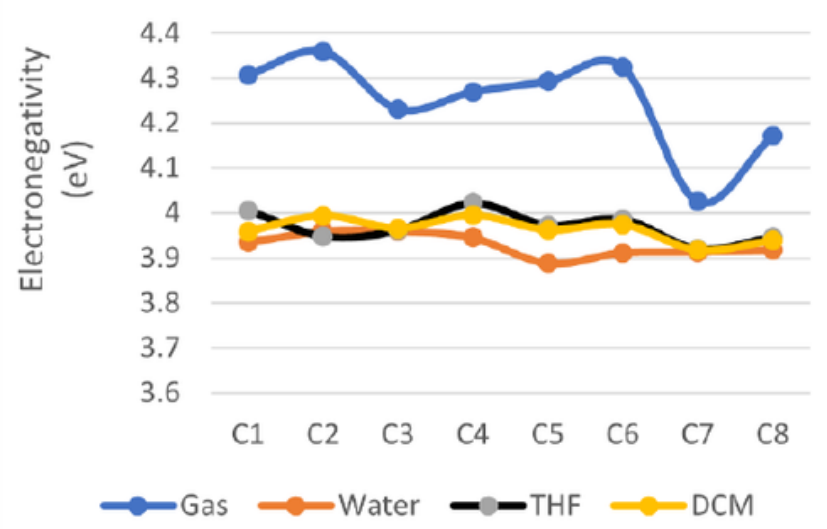

b Trend in Ionization Potential

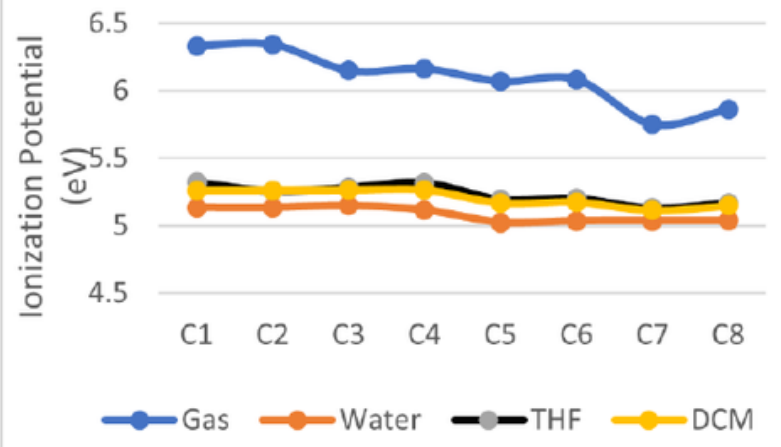

d Trend in Chemical Potential

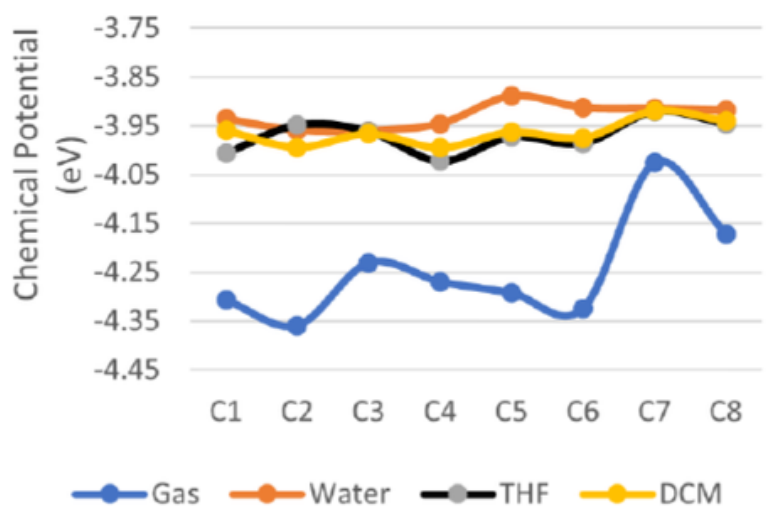

f Trend in Electrophilicity

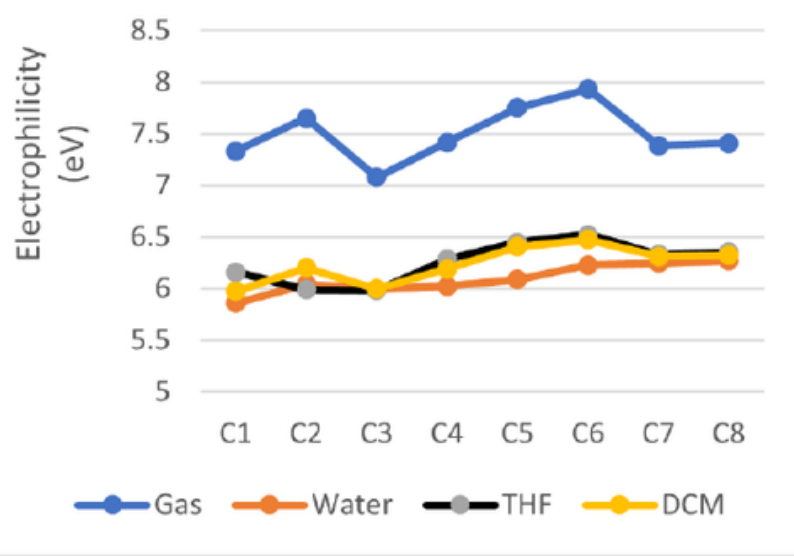

\section{Figure 6}

Trends in charge transport characteristics. (a) reorganization energy, (b) ionization potential energy, (c) hardness, (d) chemical potential energy, (e) electronegativity, and (f) electrophilicity. All energies are in electron volts $(\mathrm{eV})$.

\section{Supplementary Files}


This is a list of supplementary files associated with this preprint. Click to download.

- SupportinlnfoLatest.docx 